\title{
Electro-Thermal Model of Thermal Breakdown in Multilayered Dielectric Elastomers
}

\author{
Christensen, Line Riis; Hassager, Ole; Skov, Anne Ladegaard
}

\section{Published in:}

AIChE Journal

Link to article, DOI:

10.1002/aic. 16478

Publication date:

2019

Document Version

Peer reviewed version

Link back to DTU Orbit

Citation (APA):

Christensen, L. R., Hassager, O., \& Skov, A. L. (2019). Electro-Thermal Model of Thermal Breakdown in Multilayered Dielectric Elastomers. AIChE Journal, 65(2), 859-864. https://doi.org/10.1002/aic.16478

\section{General rights}

Copyright and moral rights for the publications made accessible in the public portal are retained by the authors and/or other copyright owners and it is a condition of accessing publications that users recognise and abide by the legal requirements associated with these rights.

- Users may download and print one copy of any publication from the public portal for the purpose of private study or research.

- You may not further distribute the material or use it for any profit-making activity or commercial gain

- You may freely distribute the URL identifying the publication in the public portal 


\section{- Abstract}

7

\title{
Electro-Thermal Model of Thermal Breakdown in Multilayered Dielectric Elastomers
}

\author{
Line Riis Christensen, Ole Hassager, and Anne Ladegaard Skov \\ Danish Polymer Centre, Department of Chemical and Biochemical Engineering, \\ Technical University of Denmark, 2800 Lyngby, Denmark
}

Energy transduction of dielectric elastomers involves minute electrical and mechanical losses, both of which potentially increase the temperature within the elastomer. Thermal breakdown of dielectric elastomers occur when heat generated therein cannot be balanced by heat loss on the surface, which is more likely to occur in stacked dielectric elastomers. In this paper an electro-thermal model of a multilayered dielectric elastomer able to predict the possible number of layers in a stack before thermal breakdown occurs is presented. Simulation results show that point of breakdown is greatly affected by an increase in surrounding temperature and applied electric field. Furthermore, if the stack diameter is large, thermal insulation of the cylindrical surface is a valid approximation. Two different expressions for the electrical conductivity are used, and it is concluded that the Frank-Kamenetskii expression is more conservative in prediction of point of breakdown than the Arrhenius expression, except at high surrounding temperature.

\section{Topical Heading: Transport Phenomena and Fluid Dynamics}

Keyword: Dielectric elastomer, Thermal breakdown, Electro-thermal model, Electrical conductivity, Multilayered

\section{Introduction}

Dielectric elastomers (DEs) are promising materials for use in various electromechanical applications as actuators, sensors, and generators ${ }^{1,2}$. Applications have a wide spectrum of sizes, ranging from micro-fluidic pumps ${ }^{3,4}$ over mm-sized Braille displays ${ }^{3,5}$ through 
DEACTIVATED

\section{Compliant}

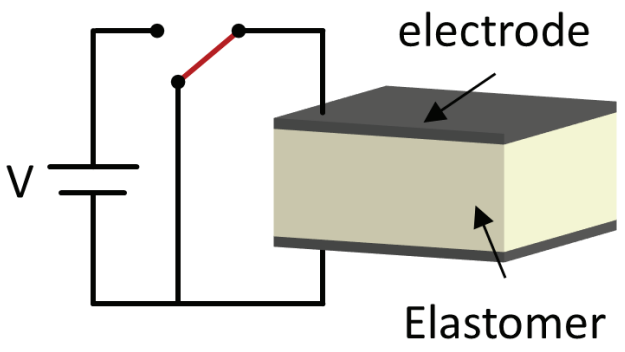

ACTIVATED

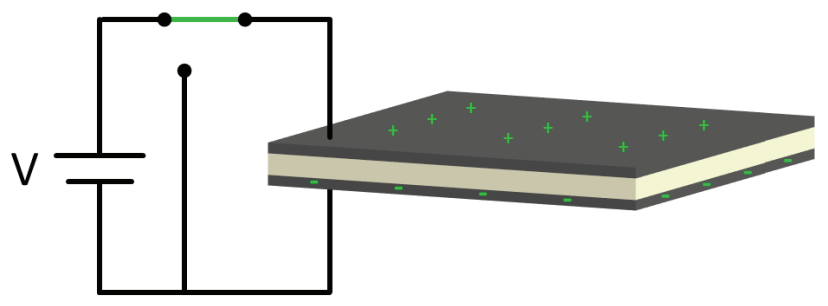

Figure 1: Illustration of the working principle of a dielectric elastomer actuator.

envisioned wave energy converters consisting of 400 meter-long tubes ${ }^{6,7}$.

A DE consists of a thin elastomer film sandwiched between two compliant electrodes, forming a capacitor capable of converting electrical energy to or from mechanical energy, i.e. a transducer ${ }^{2}$. When an external voltage is applied to the electrodes, the generated electrostatic pressure causes the electrodes to attract one another, thus decreasing thickness of the elastomer but increasing area, due to it being a nearly incompressible material. In this way, electrical energy is converted into mechanical energy. When the external voltage is removed, the elastomer regains its original shape ${ }^{1,8}$. Figure 1 illustrates the working principle of a DE actuator.

Common materials used for the elastomers include acrylic, polyurethane, natural rubber, and silicone, with silicone elastomers being those most often used, due to their high efficiency, reliability, and fast response times ${ }^{8}$. Two common types of electrodes for DEs are carbon grease and thin metal films such as gold or silver ${ }^{9}$.

Since DEs are highly flexible, they may be configured in many different ways, depending on the desired application, driving force, and operating strain ${ }^{10}$. Some common examples in this regard include extender, unimorph, bimorph, diaphragm, and tube configurations $^{3,11}$. By stacking DEs on top of each other, such that elastomer and electrode layers alternate, it is possible to increase the obtainable mechanical force in actuator mode ${ }^{9,12}$ or increase the amount of harvested energy when in generator mode ${ }^{13}$.

When applying an electric field to a DE, several types of ageing may occur, and these can be divided into two main categories: Slow degradation mechanisms and immediate breakdown mechanisms ${ }^{14}$. Slow degradation mechanisms lead to electrical trees 
and water trees ${ }^{15,16}$, which may take more than one hour from initiation until material breakdown occurs, while breakdown mechanisms are somewhat instantaneous and entail partial discharge ${ }^{17}$, electromechanical breakdown ${ }^{18}$, electrical breakdown ${ }^{19,20}$, and thermal breakdown ${ }^{21-23}$.

Several studies, both experimental and model based, have been made in which the combination of electrical and mechanical forces has been investigated, in order to examine the electrical ${ }^{24-28}$ and electromechanical ${ }^{26-32}$ breakdown of dielectric elastomers. Electrical breakdown occurs when the amount of electrical carriers in the material increases exponentially, while electromechanical breakdown is the result of an uneven thinning of the material upon application of an electrical field. However, to the best of our knowledge, the combined effect of electrical and thermal energy on the breakdown of dielectric elastomers has received very limited attention. Thus, in this work we establish the basis for investigating thermal breakdown in multilayered dielectric elastomer, by combining electrical and thermal energies in a 2D model in the commercially available FEM software COMSOL Multiphysics ${ }^{\circledR}$. After establishing the FEM model, a parameter study is conducted in which the effect of various parameters on the point of thermal breakdown is evaluated.

\section{Thermal Breakdown}

- Thermal breakdown occurs when thermal energy generated within the stack can no longer be balanced by heat loss from the stack into the surroundings, and thus the temperature within the stack will increase towards infinity ${ }^{14}$. Thermal energy is mainly generated due to Joule heating of the material, i.e. heating due to electrical resistance in the material. The amount of thermal energy generated per unit volume, $q$, in a stacked DE with $N$ layers, each of thickness $d$ and cross-section $A$, is given by Joule's law:

$$
q=\frac{V^{2}}{R N d A}=E^{2} \sigma
$$



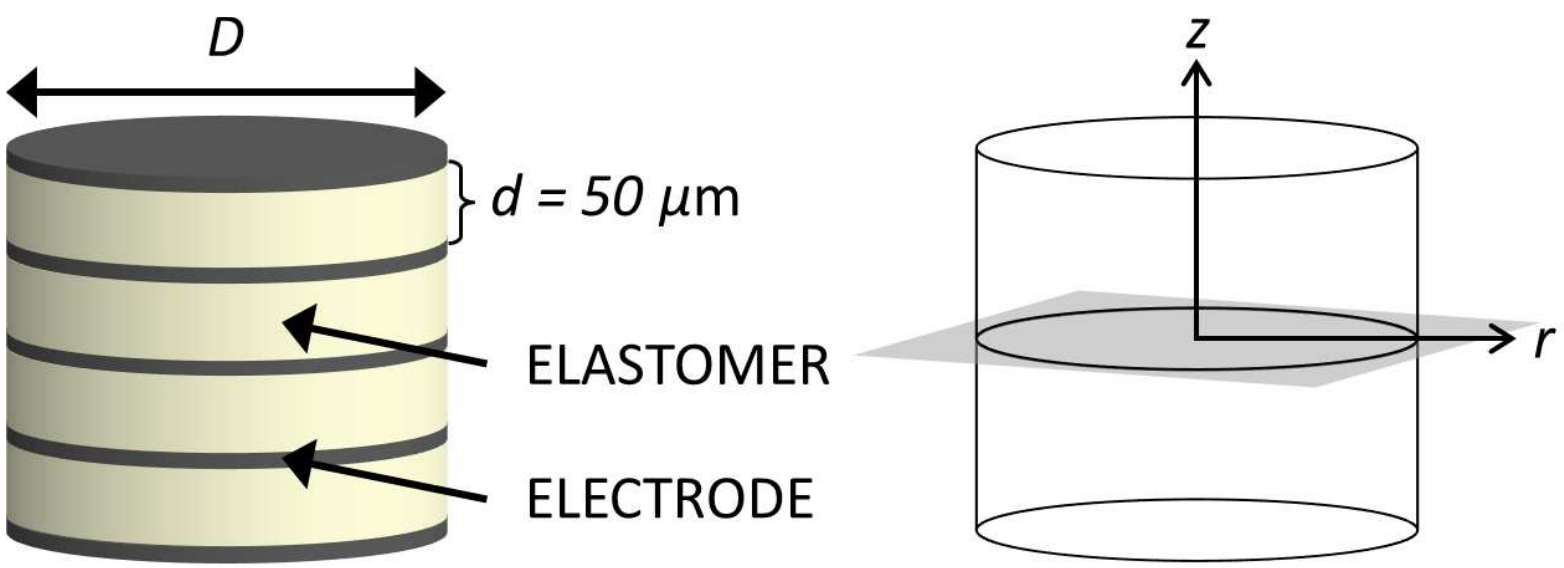

Figure 2: Left: A stacked DE with $N=4$ layers, each with a thickness of $d=50 \mu \mathrm{m}$ and a diameter of $D$. Right: Geometric illustration of the stack, with the gray plate indicating the symmetry plane in the middle of the stack.

where $V$ is the applied voltage, $R$ the material resistance, $E$ the applied electric field, and $\sigma$ the electrical conductivity of the elastomer. Thermal breakdown is especially relevant when considering stacked DEs, since multiple layers result in a larger volume and therefore more Joule heating, without an equal increase in surface area. Thus, heat loss into local surroundings decreases when $N$ increases.

\section{Model Setup}

As stated earlier, thermal breakdown is especially important when considering a multilayered DE. Thus, the configuration considered in this work is a stack of $N$ circular discs of DEs, as shown in Figure 2. The elastomer layers each have a thickness of $d=50 \mu \mathrm{m}$ and a thermal conductivity of $k=0.15 \mathrm{~W} / \mathrm{mK}^{3,33}$, which is assumed constant in terms of both position and temperature. The electrode layers are approximately three orders of magnitude thinner than the elastomer layers, and thermal conductivity of the conductive electrodes is much higher than that of the elastomer. Therefore, it is assumed that the electrodes will not be a limiting factor in heat transport within the stack, and so the effect of the electrodes is therefore neglected in this work.

The steady-state energy balance for the system at hand is as follows:

$$
k \nabla^{2} T+E^{2} \sigma(T)=0
$$


where $E$ is the electric field, $\sigma$ is the temperature dependant electrical conductivity, and $T$ is the temperature.

First term on the left side of Eq. (2) states the thermal conduction within the stack, while the second term on the left is the amount of thermal energy generated per unit volume of the stack, as given in Eq. (1).

\section{Electrical Conductivity}

The elastomer material used for validating the model presented in this paper is Elastosil RT625 from Wacker Chemie AG. The electrical conductivity of RT625 as a function of temperature was measured through dielectric relaxation spectroscopy, using a Novocontrol Alpha-A high-performance frequency analyser at $1 \mathrm{~Hz}$ and $1 \mathrm{~V} / \mathrm{mm}$. The thickness of the test sample was $1.316 \mathrm{~mm}$ and the diameter of the sample was $25 \mathrm{~mm}$. The electrodes used were $2 \mathrm{~mm}$ disposable gold-plated flat electrodes from Novocontrol Technologies with a diameter of $20 \mathrm{~mm}$ for the top electrode and $40 \mathrm{~mm}$ for the bottom electrode. The obtained experimental data are shown in Figure 3.

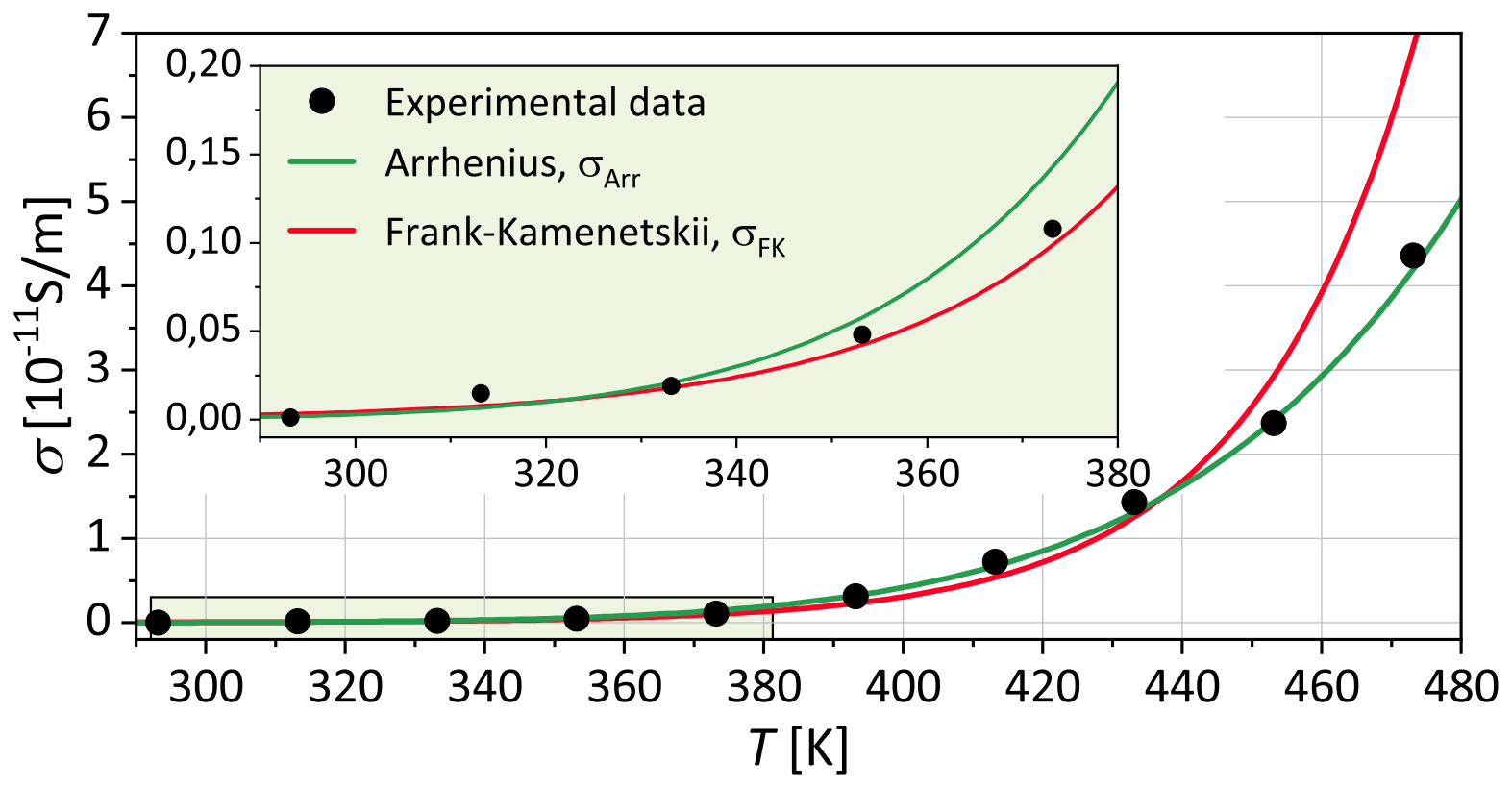

Figure 3: Experimental data (•) for the electrical conductivity of Elastosil RT625, fitted with Arrhenius expression (-), Eq. (5), and Frank-Kamenetskii expression (-), Eq. (6).

Typically the electrical conductivity of an elastomer varies with temperature in ac- 
cordance to an Arrhenius-type relation:

$$
\sigma_{\text {Arr }}(T)=\sigma_{0, \operatorname{Arr}} \exp \left(-\frac{\beta_{\text {Arr }}}{T}\right)
$$

where $\sigma_{0, \text { Arr }}$ is the pre-exponential factor, and $\beta_{\text {Arr }}$, with a unit of temperature, is the ratio between the activation energy of conduction and Boltzmann's constant ${ }^{14}$. Due to mathematical difficulties involved in integrating $\exp \left(-T^{-1}\right)$, it is common to use a FrankKamenetskii approximation of Eq. (3), which entails taking a Taylor-series expansion of the exponential around a reference temperature ${ }^{34}$. The resulting $\sigma_{\mathrm{FK}}$ function is as follows:

$$
\sigma_{\mathrm{FK}}(T)=\sigma_{0, \mathrm{FK}} \exp \left(\beta_{\mathrm{FK}} T\right)
$$

where $\beta_{\mathrm{FK}}$ has units of inverse temperature.

From the experimental data obtained, the following Arrhenius expression and FrankKamenetskii expression has been attained:

$$
\begin{aligned}
\sigma_{\text {Arr }}(T) & =1.261 \cdot 10^{-5} \frac{\mathrm{S}}{\mathrm{m}} \cdot \exp \left(-\frac{5968 \mathrm{~K}}{T}\right) \\
\sigma_{\mathrm{FK}}(T) & =1.327 \cdot 10^{-19} \frac{\mathrm{S}}{\mathrm{m}} \cdot \exp \left(0.0424 \mathrm{~K}^{-1} \cdot T\right)
\end{aligned}
$$

The two fitted expressions for the electrical conductivity is plotted along side the experimental data in Figure 3. From Figure 3 it can be seen that at low temperatures both the Arrhenius expression and the Frank-Kamenetskii expression are excellent at describing the temperature dependence of the electrical conductivity, but as temperature increases, the Frank-Kamenetskii fitting falls short. However, the mathematically simpler Frank-Kamenetskii expression is an overall good approximation of the Arrhenius function in the range from room temperature through $430 \mathrm{~K}$. 


\section{Analytical Model}

In order to obtain an analytical solution to the model put forth, it is assumed that the cylindrical surface of the DE is thermally insulated, and that the temperature within the stack only varies in height, i.e. $z$-direction (see Figure 2). Furthermore, the mathematically simpler Frank-Kamenetskii expression for the electrical conductivity obtained in Eq. (6) is utilised. The energy balance put forth in Eq. (2) therefore simplifies to:

$$
k \frac{\mathrm{d}^{2} T}{\mathrm{~d} z^{2}}+E^{2} \sigma_{\mathrm{FK}}(T)=0
$$

By assuming that the temperature on the top and the bottom of the stack is constant and equal to the temperature of the surroundings, $T\left(z= \pm \frac{1}{2} N d\right)=T_{0}$, a symmetry plane in the middle of stack is employed, and an analytical solution to Eq. (7), can be found. The analytical solution may be formulated as a relation between the maximum temperature, $T(z=0)=T_{\max }$, and a non-dimensional parameter $\lambda$ as follows:

$$
\lambda=2 \exp \left(-\theta_{\max }\right)\left(\operatorname{arctanh} \sqrt{1-\exp \left(-\theta_{\max }\right)}\right)^{2}
$$

where $\theta_{\max }=\beta_{\mathrm{FK}}\left(T_{\max }-T_{0}\right)$ is a dimensionless maximum temperature, and:

$$
\lambda=\frac{\sigma_{0, \mathrm{FK}} \exp \left(\beta_{\mathrm{FK}} T_{0}\right) \beta_{\mathrm{FK}}(E N d)^{2}}{4 k}
$$

The parameter $\lambda$ in Eq. (9) is in itself a function of several parameters, so in order to illustrate how the analytical solution obtained in Eq. (8) varies in a physical setup, it is plotted in Figure 4 as a function of: (a) $E$, (b) $T_{0}$, and (c) $N$. The base case values are $E=100 \mathrm{~V} / \mu \mathrm{m}, T_{0}=288 \mathrm{~K}$, and $N=2000$, from which one parameter is swept in each figure while keeping the remaining two constant. As the value of the sweeping parameters increase, the slope of the lines $\left(\frac{\mathrm{d} T_{\max }}{\mathrm{d} E}, \frac{\mathrm{d} T_{\max }}{\mathrm{d} T_{0}}\right.$, or $\frac{\mathrm{d} T_{\max }}{\mathrm{d} N}$, respectively) approach infinity and ends abruptly at some given parameter value, denoted as the points of breakdown. These points, are the highest values of the sweeping parameters at which it is possible to obtain steady-state solutions, since above these points the maximum temperature will be infinity. 

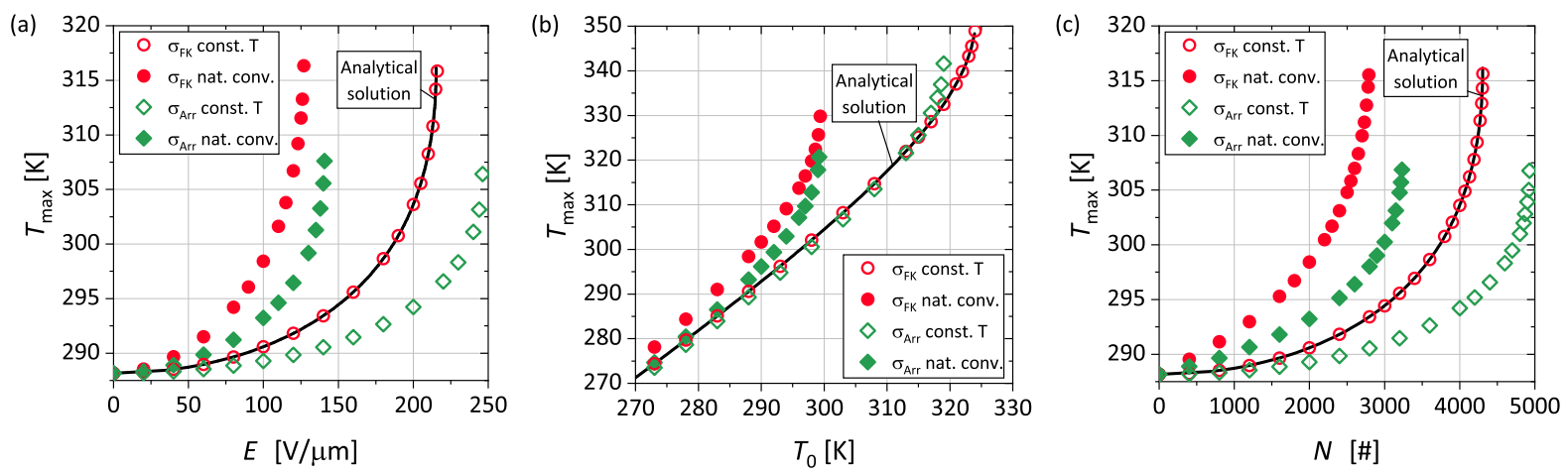

Figure 4: $T_{\max }$ within a stacked $\mathrm{DE}$ as a function of: (a) $E$, (b) $T_{0}$, and (c) $N$. Simulations using two $\sigma$-functions $\left(\sigma_{\mathrm{FK}}(\bullet, \bigcirc)\right.$ and $\left.\sigma_{\mathrm{Arr}}(\diamond, \diamond)\right)$ and two boundary conditions on the top and bottom (constant temperature $(O, \diamond)$ and natural convection $(\bullet, \diamond))$ are shown, as well as the analytical solution $(-)$. The base case values are $E=100 \mathrm{~V} / \mu \mathrm{m}, T_{0}=288 \mathrm{~K}$, and $N=2000$, from which one parameter is swept while keeping the remaining constant. Thermal insulation on the cylindrical surface is assumed.

153 is: is:

For the analytical model the breakdown points are $E_{\mathrm{BD}}=215 \mathrm{~V} / \mu \mathrm{m}, T_{0, \mathrm{~B}}=324 \mathrm{~K}$, and $N_{\mathrm{BD}}=4305$.

It should be emphasized that the breakdown values presented here are for a steadystate breakdown, thus thermal breakdown will occur over time at parameter values higher than the steady-state breakdown values.

\section{Simulated Model}

In order to obtain more complex and realistic results than the analytical solution, the model stated in Eq. (2) is implemented into the commercial finite element simulation software COMSOL Multiphysics ${ }^{\circledR}$. In COMSOL Multiphysics ${ }^{\circledR}$ it is utilized that the geometry of the multilayered stack of dielectric elastomer is 2D axisymmetric, and thus a 2D axisymmetric model has been set up using the "Heat Transfer in Solids" module applying a heat source with the quantity specified in Eq. (1). The energy balance solved

$$
k\left[\frac{1}{r} \frac{\partial}{\partial r}\left(r \frac{\partial T}{\partial r}\right)+\frac{\partial^{2} T}{\partial z^{2}}\right]+E^{2} \sigma(T)=0
$$

where both the Arrhenius expression and the Frank-Kamenetskii expression for the electrical conductivity has been used. 


\section{Validation of Numerical Simulation}

The analytical solution from Eq. (8) is used to verify simulated results of the same setup in COMSOL Multiphysics ${ }^{\circledR}$. It is therefore assumed that the cylindrical surface of the stack is thermally insulated, and the temperature on the top and bottom of the stack is constant and equal to the surroundings. Furthermore, the Frank-Kamenetskii expression for the electrical conductivity given in Eq. (6) is used.

The simulated results using $\sigma_{\mathrm{FK}}$ and $T\left(z= \pm \frac{1}{2} N d\right)=T_{0}$ are shown in Figure 4 , and it can be seen that these are in full agreement with the analytical solution obtained for all three varied parameters.

\section{Including Natural Convection as Means of Heat Transfer}

Instead of using the crude approximation that the temperature at the top and bottom of the DE stack is equal to the temperature of the surroundings, a more realistic model may be obtained by including natural convection on the top and bottom of the stack. The heat transfer functions used are as follows ${ }^{35}$ :

$$
\begin{aligned}
h_{\mathrm{t}} & =2.44 \mathrm{~W} / \mathrm{m}^{2} \mathrm{~K}\left(T_{\mathrm{t}}-T_{0}\right)^{0.25} \\
h_{\mathrm{b}} & =1.31 \mathrm{~W} / \mathrm{m}^{2} \mathrm{~K}\left(T_{\mathrm{b}}-T_{0}\right)^{0.25}
\end{aligned}
$$

where $T_{\mathrm{t}}$ and $T_{\mathrm{b}}$ are temperatures at the top and bottom plates, respectively. Simulated results using natural convection as boundary conditions are shown in Figure 4 . In all three cases, when varying $E, T_{0}$, or $N$, it is notable that results from simulations with natural convection have a lower breakdown point than simulations where $T\left(z= \pm \frac{1}{2} N d\right)=T_{0}$ is assumed. When assuming a constant temperature at the top and bottom, the assumption effectively used is that all excess thermal energy is removed from the surfaces, i.e. perfect heat transfer. However, with natural convection as the boundary condition, the heat transfer is no longer perfect, and so the temperature at the top and bottom will be higher than the surroundings, thereby leading to a higher $T_{\max }$ and thus lower breakdown point. 

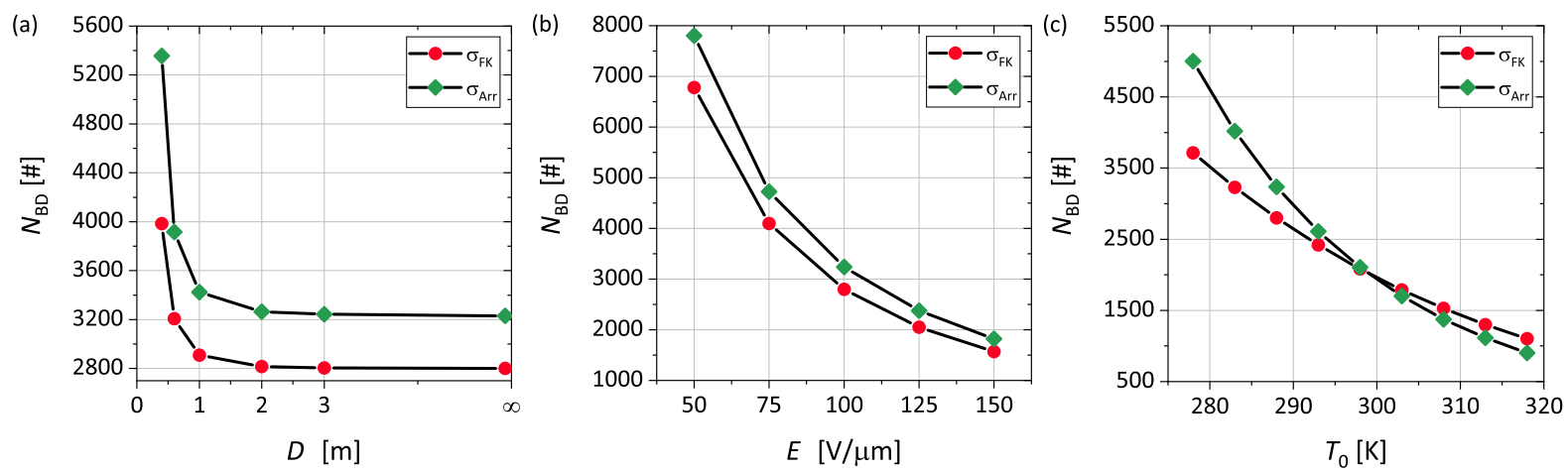

Figure 5: $N_{\mathrm{BD}}$ as a function of: (a) $D$, (b) $E$, and (c) $T_{0}$ for a stacked $\mathrm{DE}$ with natural convection on the top and bottom, according to Eq. (11) and (12). Two fittings of the electrical conductivity has been used in the simulations; Frank-Kamenetskii $(\bullet)$ and Arrhenius $(\bullet)$. The base case values are $E=100 \mathrm{~V} / \mu \mathrm{m}, T_{0}=288 \mathrm{~K}$, and $D=\infty$ (thermal insulation on the cylindrical surface), from which one parameter is swept while keeping the remaining constant.

\section{Significance of Expression for Electrical Conductivity}

Up to this point, the Frank-Kamenetskii equation for electrical conductivity, $\sigma_{\mathrm{FK}}$, has been used. However, as stated earlier, this expression is an approximation of the more realistic Arrhenius equation, $\sigma_{\text {Arr }}$. Therefore, simulations using $\sigma_{\text {Arr }}$ as given in Eq. (5) were performed in COMSOL Multiphysics ${ }^{\circledR}$, and the results obtained are shown in Figure 4 .

By comparing results from simulations where $\sigma_{\mathrm{FK}}$ is used to ones where $\sigma_{\text {Arr }}$ is used, when varying $E$ and $N$ (Figure 4 (a) and (c)), it is evident that results using $\sigma_{\mathrm{FK}}$ always underestimate the breakdown value of $E$ or $N$, for both cases of boundary conditions. When varying the surrounding temperature (Figure 4 (b)), results using $\sigma_{\text {FK }}$ slightly overestimate the maximum temperature at low $T_{0}$, but at high $T_{0}$ the maximum temperature is underestimated. Consequently, $T_{0, \mathrm{BD}}$ is overestimated with Frank-Kamenetskii approximated results compared to Arrhenius fitted results. This crossover of the Arrhenius and Frank-Kamenetskii fitted results is assigned to the crossover in the fittings of $\sigma_{\mathrm{Arr}}$ and $\sigma_{\mathrm{FK}}$ in Figure 3. However, $\sigma_{\mathrm{FK}}$ is an acceptable approximation of $\sigma_{\mathrm{Arr}}$ as long as $T_{0}$ is not too high. 


\section{Parameter Study}

As mentioned earlier, thermal breakdown is more prone to occur when DEs are stacked, so a parameter study is performed in order to investigate how different design and operating parameters affect the possible amount of layers in a stacked DE before thermal breakdown occurs, hence $N_{\mathrm{BD}}$.

\section{Diameter}

Instead of assuming thermal insulation on the cylindrical surface of the stack, natural convection is also assumed to occur on this surface, with the following heat transfer function $^{35}$ :

$$
h_{\mathrm{c}}=1.97 \mathrm{~W} / \mathrm{m}^{2} \mathrm{~K}\left(T_{\mathrm{c}}-T_{0}\right)^{0.25}
$$

where $T_{\mathrm{c}}$ is the temperature on the cylindrical surface of the stacked DE. Figure 5 (a) shows results from simulations in COMSOL Multiphysics ${ }^{\circledR}$ when varying the diameter of the stack, $D . N_{\mathrm{BD}}$ decreases significantly when increasing $D$ for both electrical conductivity fittings. When the stack diameter approaches zero, a stack with an infinite amount of layers could theoretically be constructed, because the thermal energy generated within the stack never exceeds the amount of energy transferred away at the surface, due to the fact that the ratio between surface area and volume approaches infinity. On the contrary, when the stack diameter approaches infinity, the amount of layers possible asymptotically approaches the $N_{\mathrm{BD}}$ value obtained when assuming thermal insulation on the cylindrical surface of the stack. This value is 2800 layers when using $\sigma_{\mathrm{FK}}$ and 3230 layers when using $\sigma_{\text {Arr }}$. For the remaining simulations, thermal insulation on the cylindrical surface is used, since this minimizes simulation time.

\section{Electric Field}

A second important parameter is the applied electric field and its effect on $N_{\mathrm{BD}}$, as shown in Figure 5 (b). It is evident that $N_{\mathrm{BD}}$ decreases as $E$ increases. This is explained by Eq. (1), which states that the amount of generated energy increases with electric field 
squared. Thus, when more energy is generated, $T_{\max }$ increases, and fewer layers can therefore be stacked before thermal breakdown occurs.

\section{Temperature of Surroundings}

The third examined parameter is the temperature of the surroundings, with the results as shown in Figure 5 (c). It is notable that $N_{\mathrm{BD}}$ decreases when $T_{0}$ increases. The driving force for natural convection is the difference in temperature between surroundings and stack surface, as seen in Eq. (11) and (12). Thus, when the temperature of the surroundings is increased, the driving force is decreased. Consequently, the temperature within the stack is increased and thermal breakdown occurs. It should be noted that once again, the crossover of results with $\sigma_{\mathrm{FK}}$ and $\sigma_{\text {Arr }}$ is seen, as explained earlier.

\section{Discussion}

The lowest value of $N_{\mathrm{BD}}$ obtained in the results shown in Figure 5 is $N_{\mathrm{BD}}=904$ at $T_{0}=$ $318 \mathrm{~K}, E=100 \mathrm{~V} / \mu \mathrm{m}$, and with thermal insulation on the cylindrical surface. However, this amount of layers is far beyond the amount currently seen in any applications; for example, SBM Offshore has built a wave energy harvester with a maximum number of 300 layers $^{7}$.

The overestimation of the possible number of layers predicted by simulations compared to experimental results may be explained by the fact that no mechanical deformation of the stack is taken into consideration in the model presented herein. Modelling the electromechanical coupling of dielectric elastomers is addressed multiple times in the literature, e.g by Hoffstadt and Maas ${ }^{36}$, Dorfmann and Ogden ${ }^{37,38}$, Zhao and Suo ${ }^{39}$, and Qu and $\mathrm{Suo}^{29}$. If the electro-mechanical coupling was included in the electro-thermal model presented in this work, the electric field would increase due to compression of the elastomer layer. Along side an increase in the electric field, the amount of energy generated by Joule heating, i.e. Eq. (1), would also increase leading to higher temperatures within the stack and thus less possible numbers of stacked layers. Consequently, the point of 
thermal breakdown, $N_{\mathrm{BD}}$, would decrease considerably, if the electro-mechanical coupling had been included as well.

Furthermore, the elastomer material is assumed not to have any impurities or inhomogeneous regions, which are inevitable in real-life products. Imperfections would lead to a lower $N_{\mathrm{BD}}$, since these areas of impurities or inhomogeneous regions will inherently have a higher thermal conductivity and thus serve as hotspots in the material. Last but not least, the model presented herein does not take into account any thermal degradation processes that may take place in the elastomer when the temperature of the material is elevated. Thus, the importance of the results presented lies not in the specific values of $N_{\mathrm{BD}}$ obtained but rather in the trend obtained when varying a given parameter.

\section{Conclusion}

In this paper, an electro-thermal model of a stacked DE with $N$ layers has been presented, which is able to predict the point of thermal breakdown. Two types of fitting functions for electrical conductivity have been used, and it can be concluded that the use of the mathematically simpler Frank-Kamenetskii approximation is acceptable, albeit conservative, except at high surrounding temperatures. A parameter study was conducted from which it can be concluded that if the diameter of the stack is large, it is suitable to assume thermal insulation of the cylindrical surface of the stack. Furthermore, it has been found that increasing the applied electric field or the temperature of the surroundings greatly decreases the possible number of layers in a stacked DE.

\section{Acknowledgements}

The authors gratefully acknowledge financial support from Aage and Johanne LouisHansens Fond, and they would also like to thank senior researcher Liyun Yu at DTU for performing the electrical conductivity measurements. 
$\beta \quad$ Factor in $\sigma_{\mathrm{FK}}(T)\left[\mathrm{K}^{-1}\right]$ or $\sigma_{\mathrm{Arr}}(T)[\mathrm{K}]$

$\lambda$ Dimensionless parameter in analytical solution [-]

$\sigma \quad$ Electrical conductivity $[\mathrm{S} / \mathrm{m}]$

$\sigma_{0} \quad$ Factor in $\sigma_{\mathrm{FK}}(T)$ or $\sigma_{\mathrm{Arr}}(T)[\mathrm{S} / \mathrm{m}]$

$\theta \quad$ Dimensionless temperature [-]

A Cross-section area of DE stack $\left[\mathrm{m}^{2}\right]$

$d$ Thickness of DE [m]

$D \quad$ Diameter of stack [m]

E Electric field $[\mathrm{V} / \mathrm{m}]$

$h \quad$ Heat transfer function $\left[\mathrm{W} / \mathrm{m}^{2} \mathrm{~K}\right]$

$k$ Thermal conductivity $[\mathrm{W} / \mathrm{mK}]$

$N \quad$ Amount of layers [\#]

$q \quad$ Generated thermal energy pr. volume $\left[\mathrm{W} / \mathrm{m}^{3}\right]$

$R \quad$ Resistance $[\Omega]$

$T$ Temperature $[\mathrm{K}]$

$V \quad$ Voltage $[\mathrm{V}]$

\section{Subscripts}

Arr Arrhenius equation

b Bottom surface of DE stack

BD Breakdown

c Cylindrical surface of DE stack

FK Frank-Kamenetskii approximation

$\max$ Maximum

t $\quad$ Top surface of DE stack

$0 \quad$ Surroundings

\section{${ }_{274}$ References}

1 Pelrine R, Kornbluh RD, Joseph JP. Electrostriction of polymer dielectrics with compliant electrodes as a means of actuation. Sensors Actuators A Phys 1998;64(1):77-85. 
2 Carpi F, Rossi DD, Kornbluh R, Pelrine R, Sommer-Larsen P (Editors) Dielectric elastomers as electromechanical transducers. Elsevier Ltd, Oxford, 1st edition, 2008.

3 Brochu P, Pei Q. Advances in dielectric elastomers for actuators and artificial muscles. Macromol Rapid Commun 2010;31(1):10-36.

4 Xia F, Tadigadapa S, Zhang QM. Electroactive polymer based microfluidic pump. Sensors Actuators, A Phys 2006;125(2):346-352.

5 Choi HR, Kim D, Chuc NH, Vuong NHL, Koo J, Nam JD, Lee Y. Development of integrated tactile display devices. Proc SPIE 2009;7287(1):72871C.

6 Prahlad H, Kornbluh R, Pelrine R, Stanford S, Eckerle J, Oh S. Polymer power: dielectric elastomers and their applications in distributed actuation and power generation. In: Proc. ISSS. Bangalore, India, 2005; 100-107.

7 Wattez A, Van Kessel R. Using electro active polymers to transform wave energy conversion. In: Offshore Technol. Conf. Houston, Texas, 2016; 2-5.

8 Madsen FB, Daugaard AE, Hvilsted S, Skov AL. The current state of silicone-based dieletric elastomer transducers. Macromol Rapid Commun 2016;37(5):378-413.

9 Rosset S, Shea HR. Flexible and stretchable electrodes for dielectric elastomer actuators. Appl Phys A $2013 ; 110(2): 281-307$.

10 Kornbluh RD, Pelrine R, Prahlad H, Wong-Foy A, McCoy B, Kim S, Eckerle J, Low T. Dielectric elastomers: stretching the capabilities of energy harvesting. MRS Bull 2012;37(3):246-253.

11 Romasanta LJ, Lopez-Manchado MA, Verdejo R. Increasing the performance of dielectric elastomer actuators: a review from the materials perspective. Prog Polym Sci 2015;51:188-211.

12 Carpi F, Salaris C, De Rossi D. Folded dielectric elastomer actuators. Smart Mater Struct 2007; 16(2):S300-S305.

13 Jean P, Wattez A, Ardoise G, Melis C, Van Kessel R, Fourmon A, Barrabino E, Heemskerk J, Queau JP. Standing wave tube electro active polymer wave energy converter. Proc SPIE 2012; 8340(1):83400C.

14 Dissado LA, Fothergill JC. Electrical degradation and breakdown in polymers. Peter Peregrinus Ltd., London, 1st edition, 1992. 
15 Fothergill JC, Eccles A, Houlgreave JA, Dissado LA. Water tree inception and its dependence upon electric field, voltage and frequency. IEE Proc A 1993;140(5):397-403.

16 Li K, Zhou K, Yang M, Huang M, He Y. The acceleration effect of temperature change on water tree propagation. In: Int. Conf. Cond. Monit. Diagnosis. Xi’an, China, 2016; 102-105.

17 Muffoletto DP, Burke KM, Zirnheld JL. Partial discharge monitoring in dielectric elastomer actuators. In: Int. Pulsed Power Conf. San Francisco, California, 2013; 1-5.

18 Huang R, Suo Z. Electromechanical phase transition in dielectric elastomers. Proc R Soc A 2012; 468(2140):1014-1040.

19 Skov AL, Yu L. Optimization techniques for improving the performance of silicone-based dielectric elastomers. Adv Eng Mater 2017;1700762:1-21.

20 Razak AHA, Yu L, Skov AL. Voltage-stabilised elastomers with increased relative permittivity and high electrical breakdown strength by means of phase separating binary copolymer blends of silicone elastomers. RSC Adv 2017;7(29):17848-17856.

21 Zakaria SB, Morshuis PHF, Benslimane MY, Gernaey KV, Skov AL. The electrical breakdown of thin dielectric elastomers: thermal effects. Proc SPIE 2014;9056:90562V.

22 La TG, Lau GK. Very high dielectric strength for dielectric elastomer actuators in liquid dielectric immersion. Appl Phys Lett 2013;102(19):192905.

23 La TG, Lau GK. Inhibiting electro-thermal breakdown of acrylic dielectric elastomer actuators by dielectric gel coating. Appl Phys Lett 2016;108(1):12903.

24 Gatti D, Haus H, Matysek M, Frohnapfel B, Tropea C, Schlaak HF. The dielectric breakdown limit of silicone dielectric elastomer actuators. Appl Phys Lett 2014;104(5).

25 Huang J, Shian S, Diebold RM, Suo Z, Clarke DR. The thickness and stretch dependence of the electrical breakdown strength of an acrylic dielectric elastomer. Appl Phys Lett 2012;101(12):3-6.

26 Koh SJA, Zhao X, Suo Z. Maximal energy that can be converted by a dielectric elastomer generator. Appl Phys Lett 2009;94(26):36-38.

27 Liu LW, Zhang Z, Liu YJ, Leng JS. Failure modeling of folded dielectric elastomer actuator. Sci China Physics, Mech Astron 2014;57(2):263-272.

28 Moscardo M, Zhao X, Suo Z, Lapusta Y. On designing dielectric elastomer actuators. J Appl Phys 2008;104(9):1-7. 
$29 \mathrm{Qu} \mathrm{S}$, Suo Z. A finite element method for dielectric elastomer transducers. Acta Mech Solida Sin 2012;25(5):459-466.

30 Yong H, He X, Zhou Y. Electromechanical instability in anisotropic dielectric elastomers. Int J Eng Sci 2012;50(1):144-150.

31 Zhao X, Suo Z. Method to analyze electromechanical stability of dielectric elastomers. Appl Phys Lett 2007;91:061921.

32 Zhu J, Stoyanov H, Kofod G, Suo Z. Large deformation and electromechanical instability of a dielectric elastomer tube actuator. J Appl Phys 2010;108(7):1-6.

33 Mark JE (Editor) Polymer data handbook. Oxford University Press, New York, NY, 1st edition, 1999.

34 White D, Johns LE. The Frank-Kamenetskii approximation. Chem Eng Sci 1987;42(7):1849-1851.

35 Clement KH, Fangel P, Jensen AD, Thomsen K. Kemiske enhedsoperationer. Polyteknisk Forlag, Lyngby, Denmark, 5th edition, 2009.

36 Hoffstadt T, Maas J. Analytical modeling and optimization of DEAP-based multilayer stacktransducers. Smart Mater Struct 2015;24:1-14.

37 Dorfmann A, Ogden RW. Nonlinear electroelasticity. Acta Mech 2005;174(3-4):167-183.

38 Dorfmann L, Ogden RW. Nonlinear electroelasticity: material properties, continuum theory and applications. Proc R Soc A 2017;473(2204):20170311.

39 Zhao X, Suo Z. Electrostriction in elastic dielectrics undergoing large deformation. J Appl Phys $2008 ; 104(12)$. 


\section{List of Figures}

1 Illustration of the working principle of a dielectric elastomer actuator. . .

2 Left: A stacked DE with $N=4$ layers, each with a thickness of $d=50 \mu \mathrm{m}$ and a diameter of $D$. Right: Geometric illustration of the stack, with the gray plate indicating the symmetry plane in the middle of the stack. . . .

3 Experimental data ( $)$ for the electrical conductivity of Elastosil RT625, fitted with Arrhenius expression (-), Eq. (5), and Frank-Kamenetskii expression $(-)$, Eq. (6). . . . . . . . . . . . . . .

$4 T_{\max }$ within a stacked $\mathrm{DE}$ as a function of: (a) $E$, (b) $T_{0}$, and (c) $N$. Simulations using two $\sigma$-functions $\left(\sigma_{\mathrm{FK}}(\bullet, \bigcirc)\right.$ and $\left.\sigma_{\text {Arr }}(\diamond, \diamond)\right)$ and two boundary conditions on the top and bottom (constant temperature $(\bigcirc, \diamond)$ and natural convection $(\bullet, \bullet))$ are shown, as well as the analytical solution (-). The base case values are $E=100 \mathrm{~V} / \mu \mathrm{m}, T_{0}=288 \mathrm{~K}$, and $N=2000$, from which one parameter is swept while keeping the remaining constant. Thermal insulation on the cylindrical surface is assumed. . . . . . . . . .

$5 \quad N_{\mathrm{BD}}$ as a function of: (a) $D$, (b) $E$, and (c) $T_{0}$ for a stacked DE with natural convection on the top and bottom, according to Eq. (11) and (12). Two fittings of the electrical conductivity has been used in the simulations; Frank-Kamenetskii $(\bullet)$ and Arrhenius $(\bullet)$. The base case values are $E=$ $100 \mathrm{~V} / \mu \mathrm{m}, T_{0}=288 \mathrm{~K}$, and $D=\infty$ (thermal insulation on the cylindrical surface), from which one parameter is swept while keeping the remaining constant. . . . . . . . . . . . . . . . . . . 
DEACTIVATED

Compliant

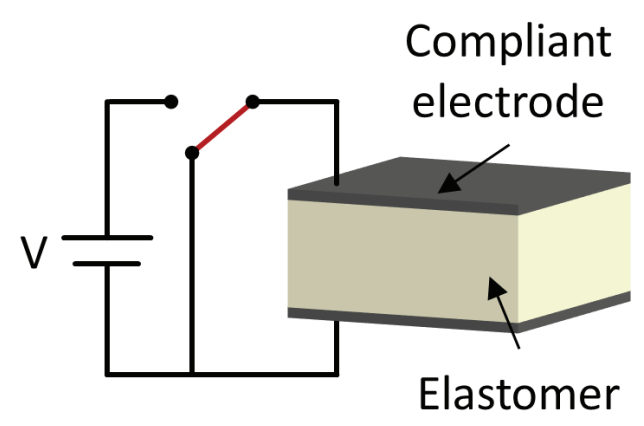

ACTIVATED

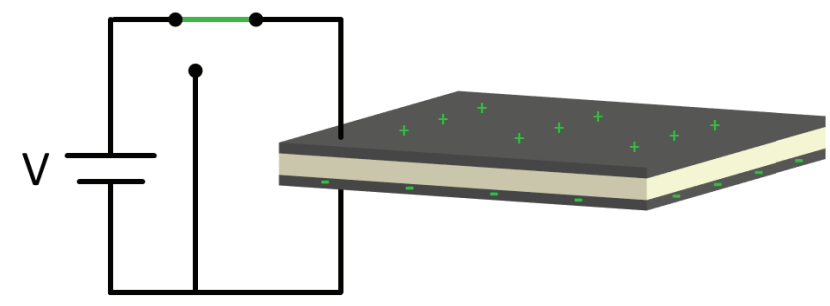



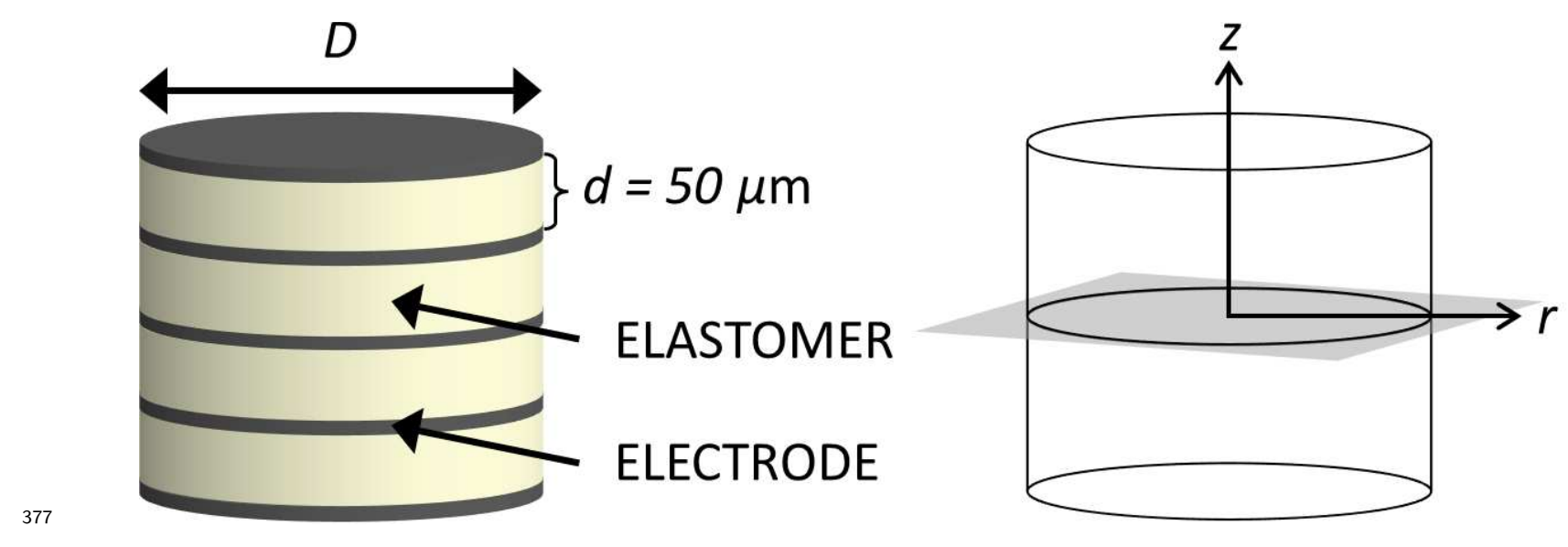


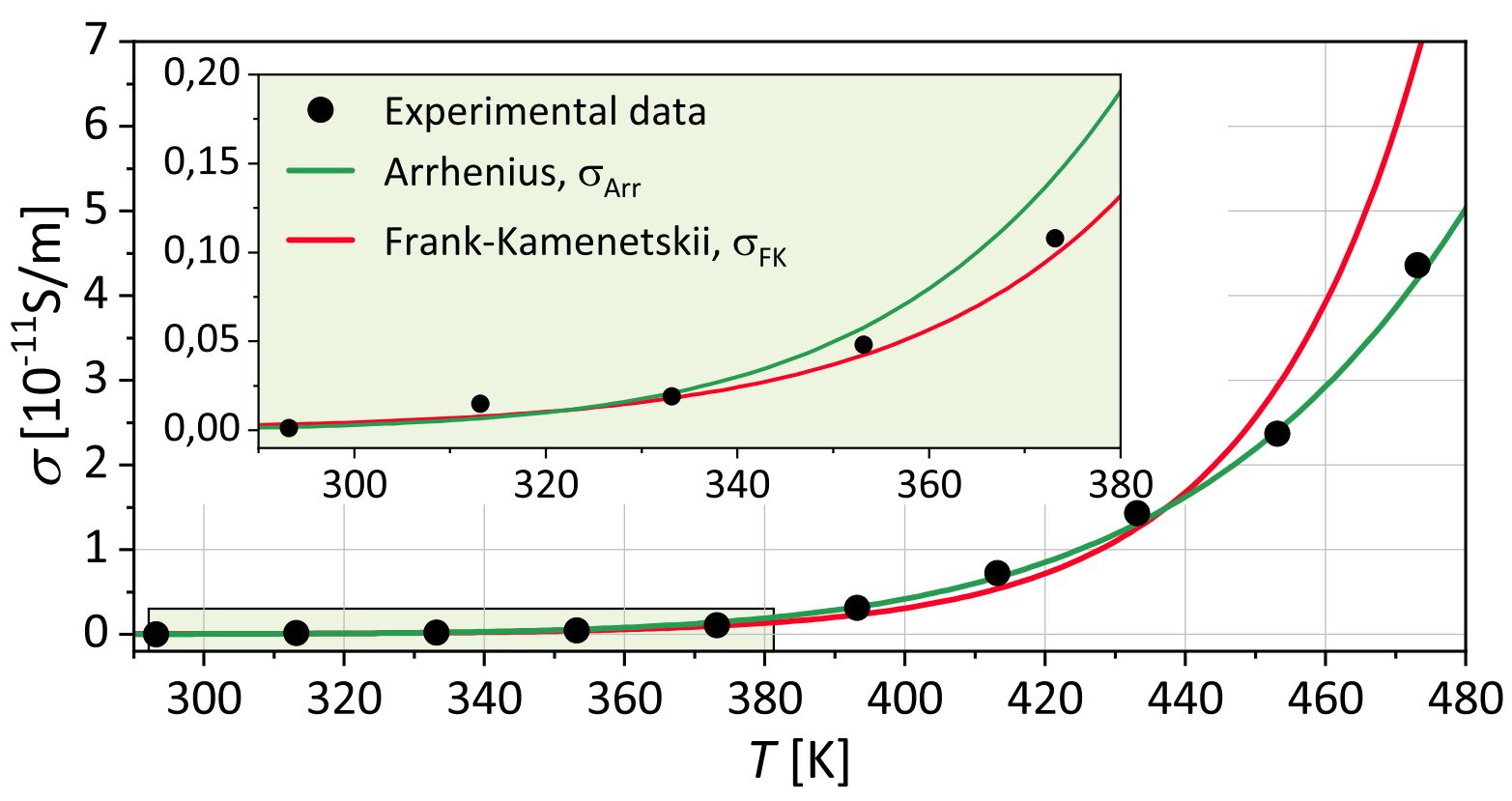


(a) 320

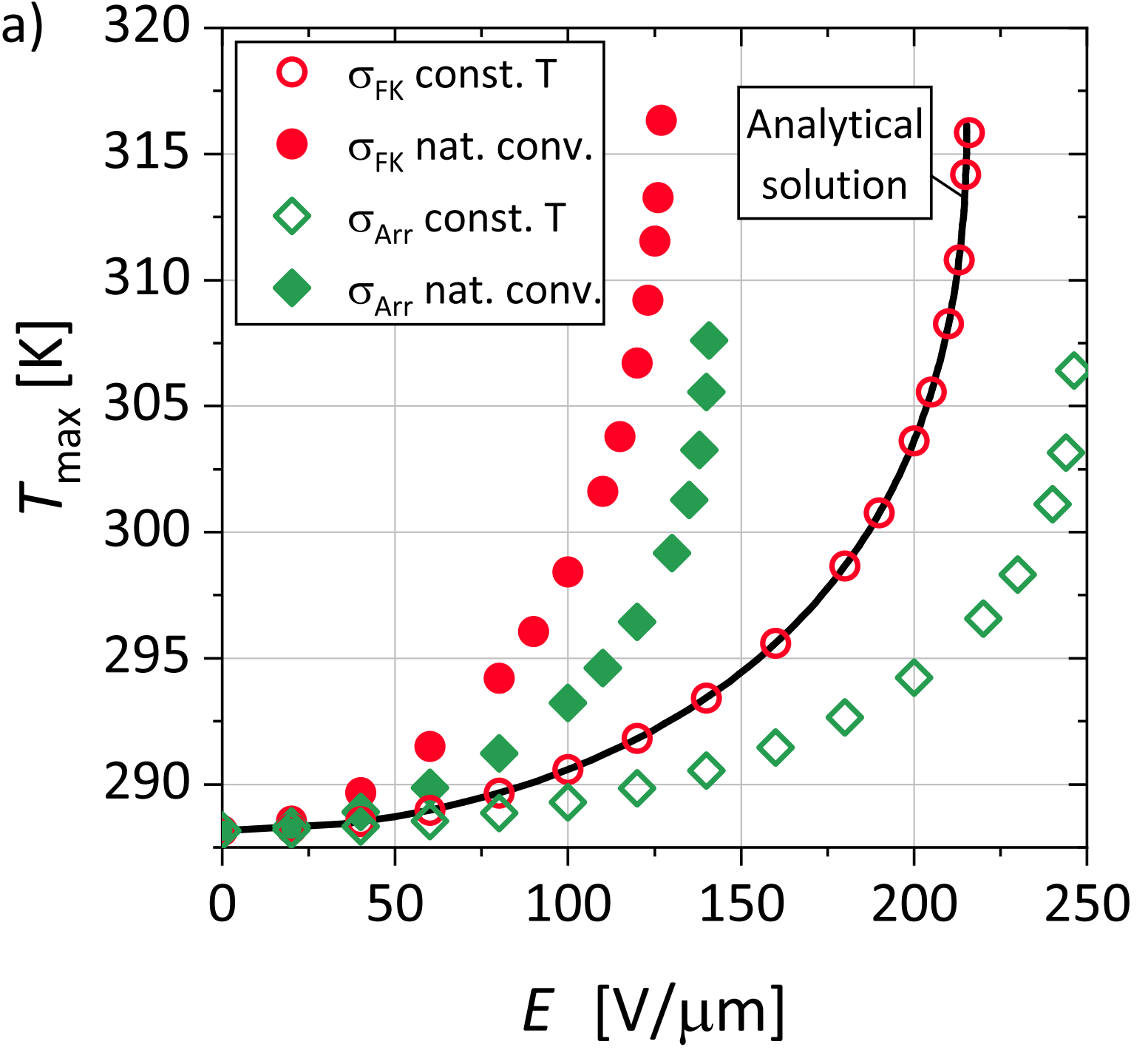




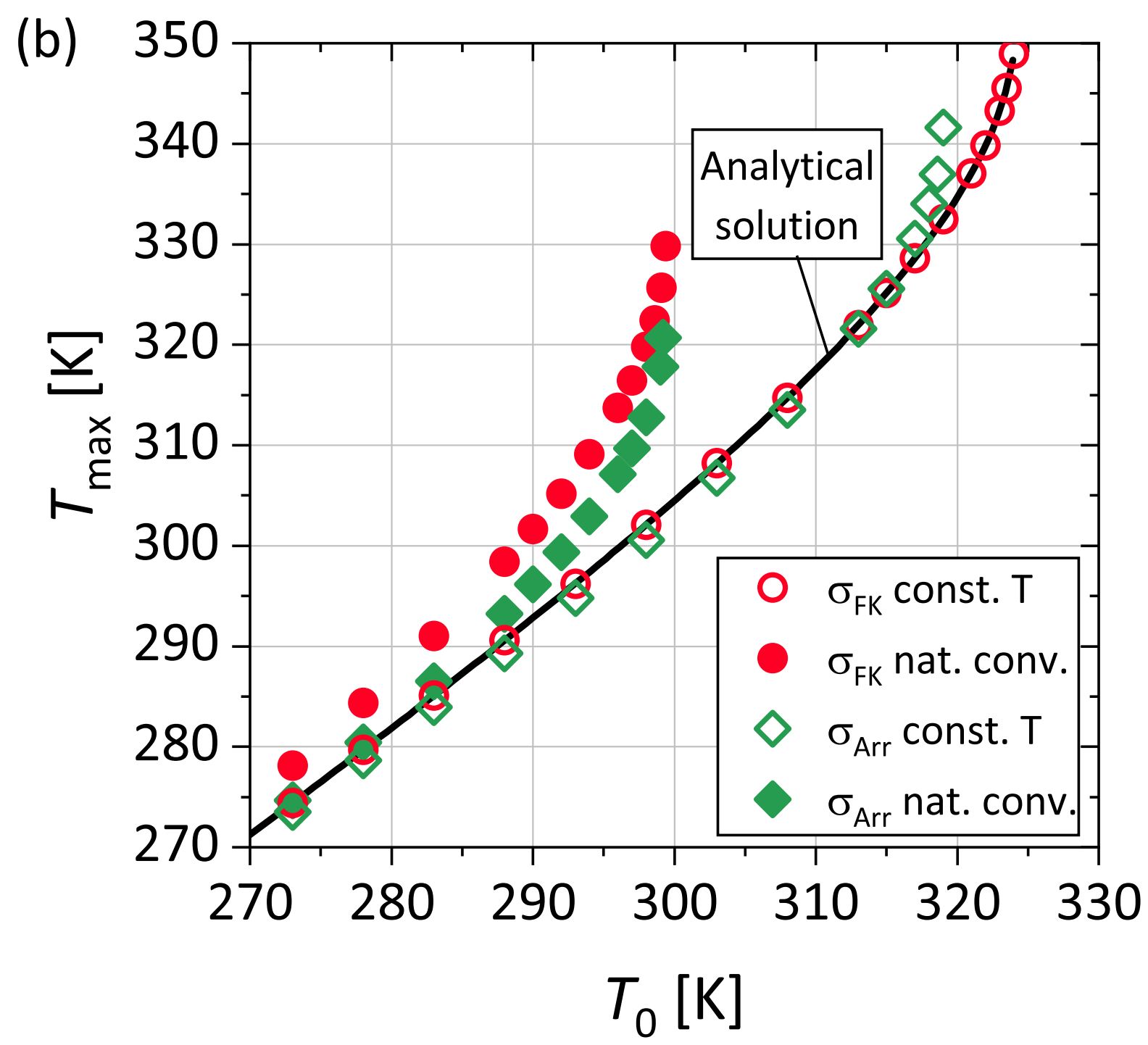




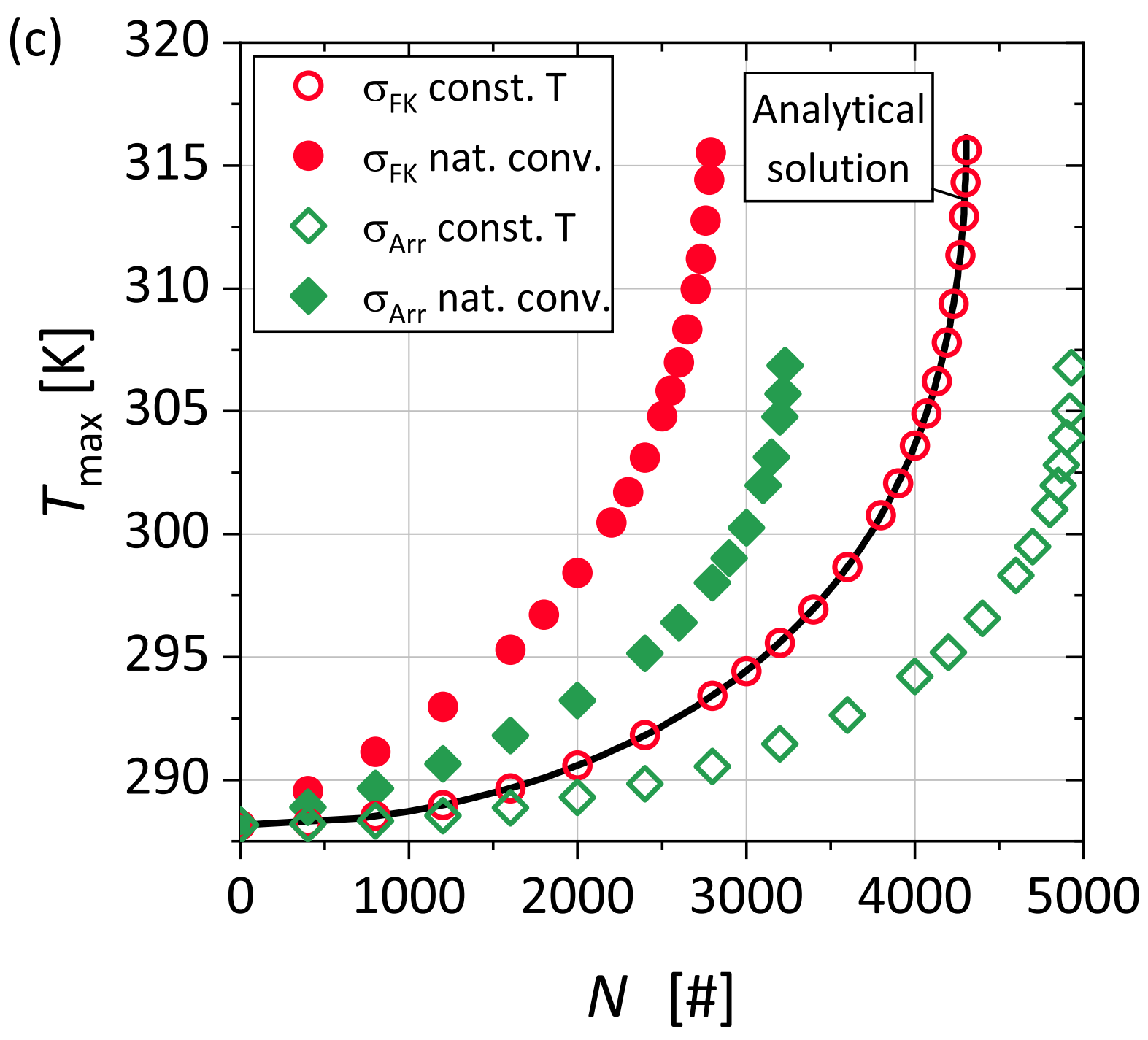




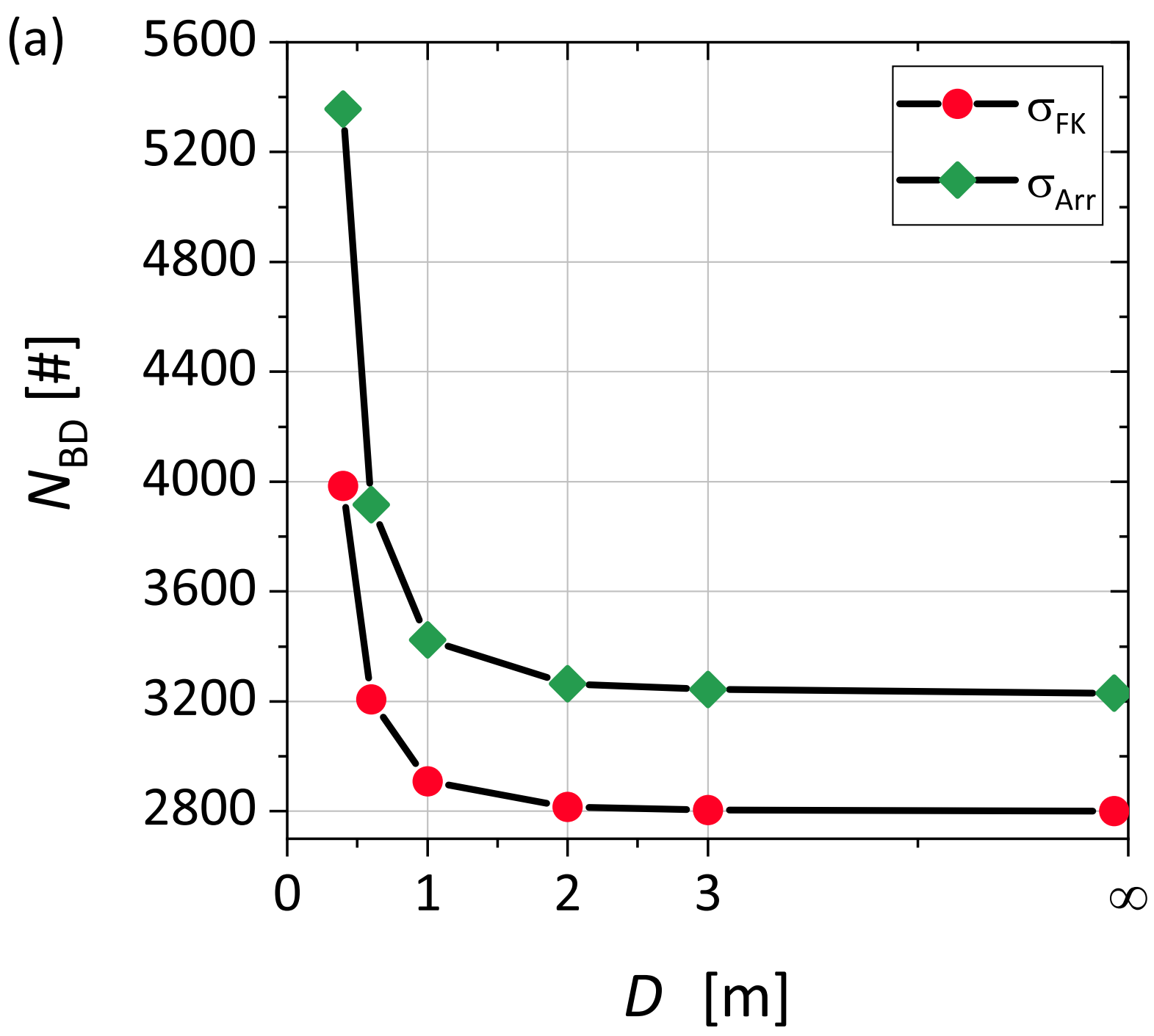




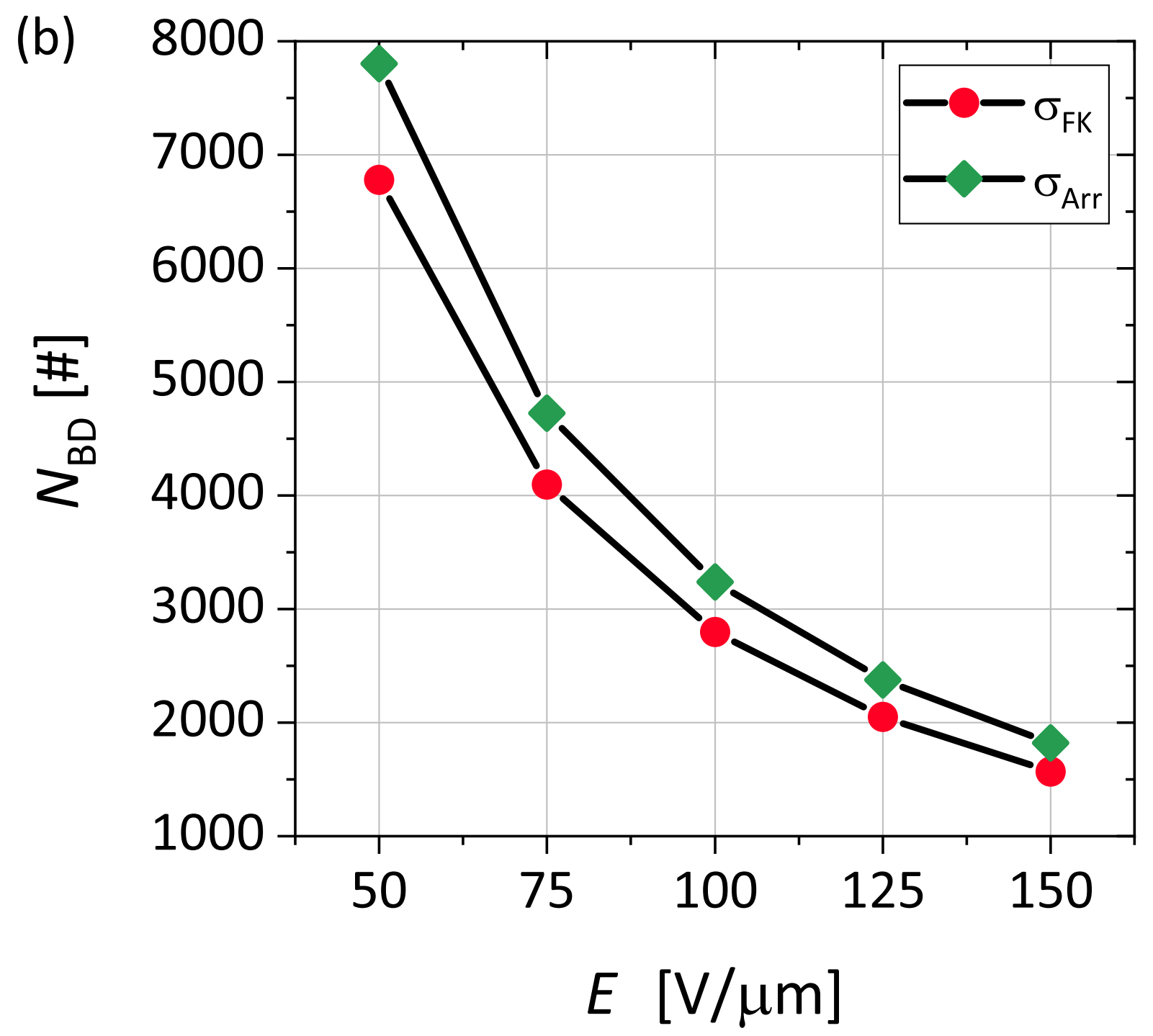




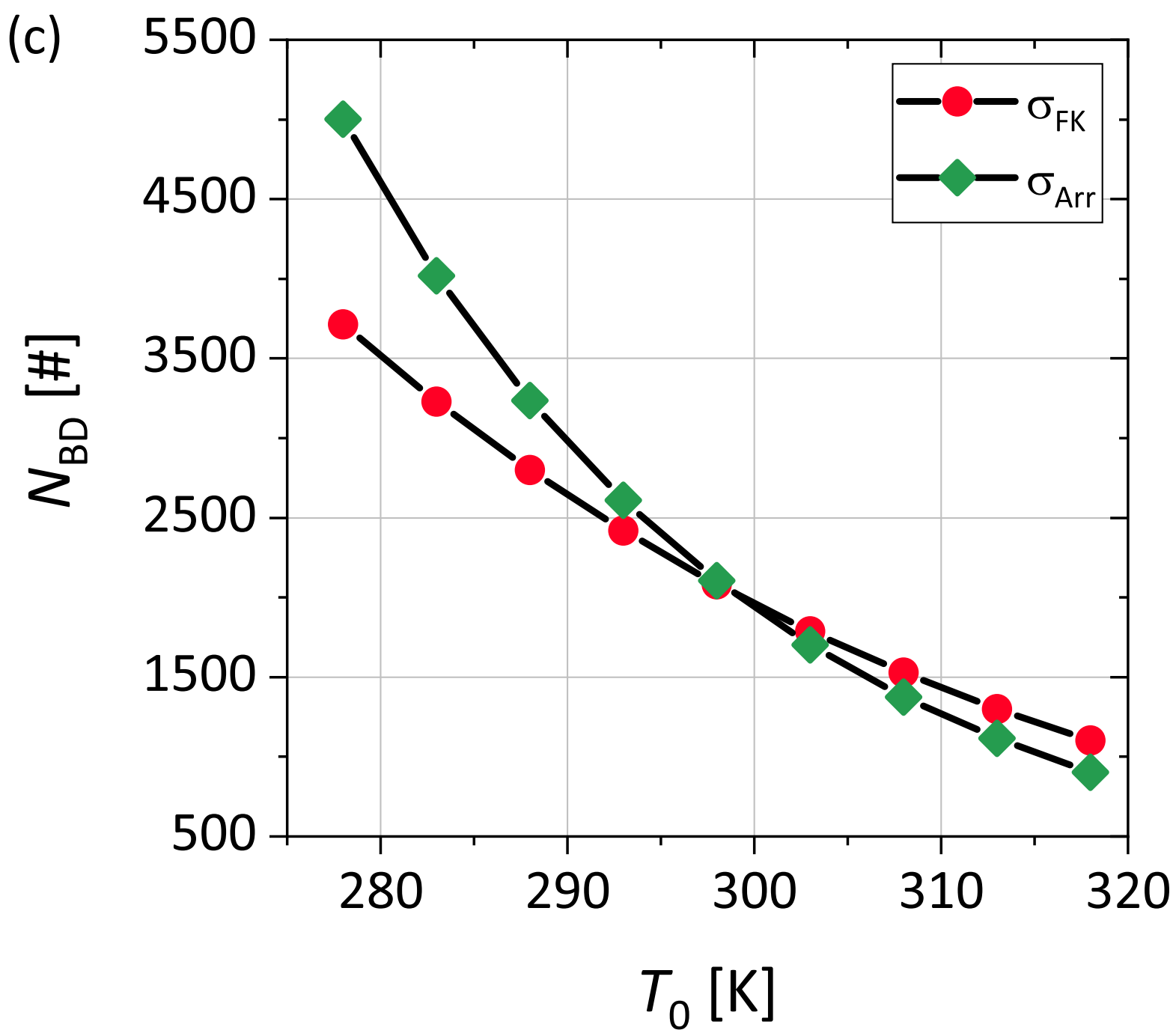

